\title{
In vivo and in vitro activity of genistein in osteoporosis
}

\author{
J iepin Wang*^, Fujun Shang**, Li Liu*, Siwang wang^, J ianbo Wang^, Qibing M ei*
}

*D epartment of Pharmacology,

School of Pharmacy, Fourth

Millitary Medical U niversity, Xi'an,

Shaanxi, PR China, 710032;

**D epartment of Cardiology,

Tangdu Hospital, Fourth Millitary

Medical U niversity, Xi'an, Shaanxi,

PR China, 710038;

Institute of M ateria M edica,

School of Pharmacy, Fourth

M illitary Medical U niversity, Xi'an,

Shaanxi, PR China, 710032

Received: 20.12 .2006

Revised: 8.5.2007

Accepted: 12.5.2007

Correspondence to:

Q ibing Mei

E-mail: pharm-mei@hotmail.com

\section{ABSTRACT}

Background: 0 steoporosis is conventionally treated with synthetic estrogens. H owever, the serious side effects of hormone replacement therapy (HRT) hampers the clinical use of estrogens. Hence, alternatives for estrogens are being explored, one of which is the isoflavone, genistein. M any studies show that genistein may exert positive effects on bone. However, there are also studies which report no overall association between genistein intake and bone marrow density (BMD) and fracture rates. The effect of genistein on bone loss is still controversial.

Aims: In this study, we evaluated both in vivo and in vitro pharmacological effects of genistein in osteoporosis.

M aterials and M ethods M TT and ALP activity assays were performed to evaluate genistein's in vitro activity on MC3T3-E1 cells. The OVX rat model was used to test genistein's in vivo effects by determination of BMD and bone calcium and phosphorus content after treatment for 12 weeks.

Results and Conclusions: The data showed that $10^{-6} \mathrm{M}$ genistein both increased the number of M C3T3-E1 cells and elevated ALP activity significantly. In vivo, 9 or $18 \mathrm{mg} / \mathrm{kg}$ doses of genistein were found to prevent osteoporosis after 12 weeks treatment. Thus, our results indicated that genistein may be an alternative for HRT in prevention of postmenopausal osteoporosis.

KEY WORDS: Genistein, MC3T3-E1 cells, osteoporosis, OVX rats.
Osteoporosis is characterized by a reduction in bone density and strength to the extent that fractures occur after minimal trauma. It is well known that estrogen deficiency as in postmenopause and ovariectomy leads to acceleration of bone resorption and rapid bone loss, resulting in the development of osteoporosis. ${ }^{[1]}$

Current therapies recommended for postmenopausal osteoporosis (PMO) treatment include supplementation with estrogen or hormone replacement therapies (ERT or HRT). Estrogen is the most potent inhibitor of bone resorption and the most widely recommended therapy to reduce the rate of postmenopausal bone loss. However, available evidence appears to suggest that the long-term use of ERT has numerous side effects. ${ }^{[2,3 \mid}$ Currently, natural alternatives with estrogen-like activities such as soy isoflavones are being investigated as possible alternatives for HRT. ${ }^{[4-6]}$ Isoflavones are compounds in plant foods, particularly soybeans, which are structurally and functionally similar to estrogens. They have recently received considerable attention for their potential use in the prevention of postmenopausal bone loss. Data from animal experiments provided evidence that soy protein can attenuate
PMO and it was suggested that isoflavones in soy might be responsible for their protective effects on bone. ${ }^{[7-9]}$ Of all the isoflavones, genistein has received the most attention. ${ }^{10]}$ Genistein (4',5,7-trihydroxyisoflavone) (1) is a major isoflavone phytochemical in some plants belonging to the leguminosae family. It is known as a phytoestrogen that is capable of binding to the estrogen receptor. ${ }^{[11}$ Much attention has been focused on the role of genistein in preventing bone loss resulting at least in part from estrogen deficiency. ${ }^{[12-14]}$ Furthermore, the findings that genistein acts as a selective estrogen receptor modulator (SERM) on osteoblastic cells ${ }^{[15]}$ and in ovariectomized (OVX) mice ${ }^{[16]}$ highlights the possibility that this isoflavone phytochemical hardly affects the uterus in the dose ranges in which it exerts estrogen-like regulatory action on bone and bone marrow metabolism. However, some studies reported no overall association between genistein intake and BMD and fracture rates. The effect of genistein on bone loss is still a controversial subject.

The purpose of this study was to determine whether the administration of genistein is capable of preventing rapid in vivo and in vitro bone loss. Cell proliferation as well as the 
expression of some biochemical parameters of osteoblastic phenotypes were monitored. The in vivo effects of genistein on BMD and bone minerals including calcium and phosphorous were also evaluated.

\section{Materials and Methods}

\section{Chemicals and animals}

All drugs were prepared in dimethylsulfoxide (DMSO) and then diluted with the medium (final DMSO concentration $\leq$ $0.05 \%(\mathrm{v} / \mathrm{v}))$. All other reagents were from Sigma Chemical Co. (St. Louis, MO, USA) unless otherwise stated. All chemicals were of analytical grade. Each experiment was repeated three times.

Forty nine-week old mature female Sprague Dawley rats (obtained from the laboratory animal center of FMMU, Xi'an China; weighing in average: $223 \pm 5.6 \mathrm{~g}$ ) were housed four to a cage under standard laboratory conditions with temperature ranging between 20 and $25^{\circ} \mathrm{C}$, relative humidity between $55-65 \%$ and a $12 \mathrm{~h}$ light / dark cycle (lights on 08:00). All rats were allowed free access to water and a pelleted commercial diet (containing $0.97 \%$ calcium, $0.85 \%$ phosphorus and $1.05 \mathrm{IU} / \mathrm{g}$ of Vitamin D3). After a week of acclimation, animals were used for studies. The experimental protocol was approved by the Ethical Committee for Animal Care of the Fourth Military Medical University. Efforts were made to minimize animal suffering and to reduce the number of animals used.

Rats were randomly allocated to six groups $(\mathrm{n}=8$ each group). ( $6 * 8=48$, earlier you said 32 animals were taken. If sham $=1$ group, $O V X=2^{\text {nd }}$ group getting vehical, groups $3,4,5$ get $4.5,9$ or $18 \mathrm{mg} / \mathrm{kg}$ genistein. After a week of recovery from the operation, Sham-operated (SH group) and one OVX group (two groups) received vehical (1\% DMSO water solutions). The remaining three OVX groups were given genistein $(4.5,9$ or 18 $\mathrm{mg} / \mathrm{kg} /$ day respectively). All rats were given both vehicle and genistein by the intragastric route. After 12 weeks of treatment, the animals were anesthetized beforehand by intraperitoneal injection of sodium pentobarbital $(45 \mathrm{mg} / \mathrm{kg}$ ).

\section{Cell cultures}

MC3T3-E1 cells (RCB1126, an osteoblast-like cell line from C57BL/6 mouse calvaria) were purchased from the American Type Culture Collection (ATCC). Cells were cultured at $37^{\circ} \mathrm{C}$ in $5 \% \mathrm{CO}_{2}$ atmosphere in Dulbecco's Modified Eagle Medium (DMEM), high glucose (Gibco, invitrogen Corp.). Unless otherwise specified, the medium contained 10\% heatinactivated fetal bovine serum (FBS), $100 \mathrm{U} / \mathrm{ml}$ penicillin, 100 $\mu \mathrm{g} / \mathrm{ml}$ streptomycin and $2 \mathrm{mM}$ L-glutamine. During subculture, the medium was replaced every three days.

\section{MTT assay}

Cells were suspended in medium and plated at a density of $3.0 \times 10^{4}$ cells/well into a 96 -well culture dish (Costar,

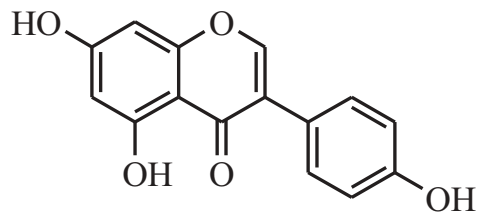

Cambridge, MA). After $8 \mathrm{~h}$, the medium was replaced with phenol red-free media containing 5\% charcoal-dextran-treated FBS (CD-FBS) supplemented with different concentrations of genistein $\left(10^{-9}-10^{-5} \mathrm{M}\right)$. After $72 \mathrm{~h}$ of culture, cell proliferation was measured by the MTT assay. ${ }^{[17]}$ This assay is based on the ability of viable cells to convert soluble 3-(4,5-dimethylthiazol-2yl)-2,5-diphenyl tetrazolium bromide (MTT) into an insoluble dark blue formazan reaction product. DMSO was then added and mixed thoroughly to dissolve the dark blue crystals. The plates were read by a microplate reader at a wavelength of $490 \mathrm{~nm}$.

\section{Alkaline phosphatase (ALP) activity}

ALP activity is a phenotypic marker for the early and mature differentiation stages of osteoblast cells. After the cells were cultured at a density of $9 \times 10^{4}$ cells/well into culture dishes for $12 \mathrm{~h}$, the medium was replaced with phenol red-free DMEM containing 5\% CD-FBS supplemented with $10^{-6} \mathrm{M}$ genistein. On days 3, 5 and 7, the medium was removed and the cell monolayer was gently washed twice with PBS. The cells were lysed with $0.2 \%$ Triton $\mathrm{X}-100$ and the lysate was centrifuged at $1 \times 10^{4} \mathrm{rpm}$ for $5 \mathrm{~min}$ at $4^{\circ} \mathrm{C}$. The clear supernatant was used for the colorimetric measurement of ALP activity and protein concentration with an ALP kit (Sigma, St. Louis, MO, USA) according to the manufacturer's instructions. ALP activity was normalized with the total protein content determined by using the Bradford protein assay with bovine serum albumin (BSA) as a standard. ${ }^{118]}$

\section{Measurement of BMD}

Femurs and tibias were removed at the time of necropsy, cleaned of soft tissue and stored at $-70^{\circ} \mathrm{C}$ until analysis. BMD analyses were performed on left legs (femur and tibia) by dual energy X-ray absorptiometry (DEXA) (DPX-IQ 7040, Lunar Corp, USA) with small animal software 1.0. The results are expressed as mean $\pm \mathrm{SE}$ (standard error).

Bone calcium, phosphorus content

The bone tissues were dried at $120^{\circ} \mathrm{C}$ for $12 \mathrm{~h}$, weighed, then dissolved in 5\% nitric acid solution. ${ }^{[19]}$ Calcium and Phosphorus levels were determined by atomic absorption spectrophotometry (Solaar M6, Thermo Electron, USA), the content was expressed as millimole per gram of dry bone.

\section{Statistical analysis}

The results were expressed as the mean \pm SE. All data was analyzed using one-way analysis of variance (ANOVA) followed by LSD t-test using SPSS statistical software (SPSS, Inc, Chicago, IL).

\section{Results}

\section{Cell proliferation assay}

The proliferation of osteoblast was evaluated using the MTT assay. Compared to the blank, cell numbers significantly increased by $28.1 \%(P<0.05)$ due to treatment with $10^{-6}$ M genistein, which was higher than other concentrations of genistein [Figure 1].

\section{ALP activity}

ALP activity was measured to study the effect of genistein on osteoblast differentiation. Our experimental results showed that ALP activity rose significantly ( $105.1 \%$ vs control, $P<0.05)$ 
after $10^{-6} \mathrm{M}$ genistein was administered for five days. However, ALP activity reached the highest level $(124.6 \%$ vs control, P < 0.01) after seven days [Figure 2].

Bone mineral density (BMD)

The effect of 12 weeks of treatment on femoral and tibial BMD is illustrated in Figure 3. Femoral and tibial BMDs were $22.7 \%$ and $17.0 \%$ lower in OVX rats than in intact controls ( $P$ $<0.01$ ), while the BMDs in rats of the genistein groups (4.5, 9 and $18 \mathrm{mg} / \mathrm{kg}$ ) were all significantly elevated and were 93.9 , 103.1 and $100.6 \%$ of the SH group respectively.

Bone calcium, phosphorus content

Bone calcium and phosphorus contentwere found to decrease with ovariectomy (90.9 and $86.8 \%$ of the SH group). After 12 weeks of treatment with genistein, bone calcium levels were $96.3,99.3$ and $99.0 \%$ of the SH group and bone phosphorus levels were $98.8,96.9$ and $95.1 \%$ of the SH group. The effect of genistein at its mid- and high doses on bone calcium levels was especially significant $(P<0.05)$ as compared to that of the low dose [Figures 4, 5].

Figure 1: MTT assay for cell proliferation after $72 \mathrm{~h}$ of drug treatment. Genistein may promote cell proliferation. At a dose of $10^{-6} \mathrm{M}$, genistein significantly increases cell numbers compared with the blank control $\left(128.1 \%\right.$ vs blank, $\left.{ }^{*} P<0.05\right)$. Data is expressed as the mean \pm SE

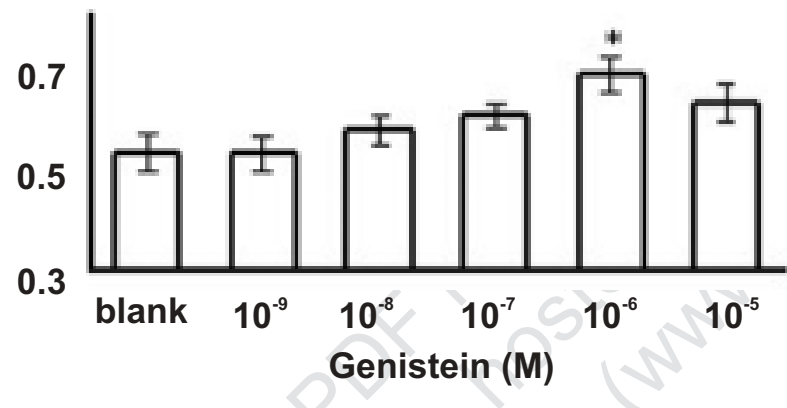

Figure 2: Effect of genistein $\left(10^{-6} \mathrm{M}\right)$ on the activity of ALP at different time points. Five day-treatment with genistein resulted in ALP activity elevated by $5.1 \%$ ( ${ }^{*} P<0.05$ vs control). After treatment for seven days, ALP activity reached the highest level observed in the study $(124.6 \%$ vs control, $\left.{ }^{* *} P<0.01\right)$. Data is expressed as the mean \pm SE.

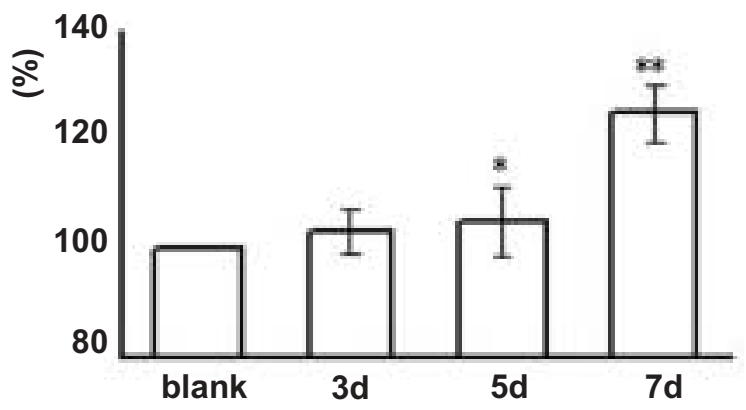

\section{Conclusion}

The present study demonstrates that genistein, an abundant soybean isoflavone, may prevent both in vivo and in vitro bone loss. Osteoblasts are the key cells involved in bone matrix

Figure 3: BMD changes after drug administration. OVX induced significant BMD decrease, which was reversed by genistein administration. The femoral BMDs in genistein-treated groups were $21.4 \%(\mathrm{~L}), 33.3 \%(\mathrm{M})$ and $30.2 \%(\mathrm{H})$ higher than that seen in OVX controls. The tibial BMDs in genistein-treated groups were $18.8 \%(\mathrm{~L})$, $23.2 \%(\mathrm{M})$ and $22.3 \%(\mathrm{H})$ higher than that seen in OVX controls. Data is expressed as the mean $\pm \mathrm{SE}$ of eight rats. ${ }^{*} P<0.05$ vs $\mathrm{SH},{ }^{* *} P<$ 0.01 vs SH. L: low dose ( $4.5 \mathrm{mg} / \mathrm{kg}), \mathrm{M}$ : mid-dose $(9 \mathrm{mg} / \mathrm{kg}), \mathrm{H}$ : high dose $(18 \mathrm{mg} / \mathrm{kg})$.

A

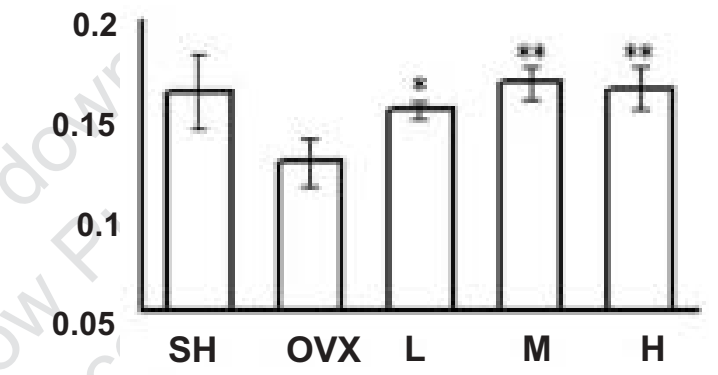

B

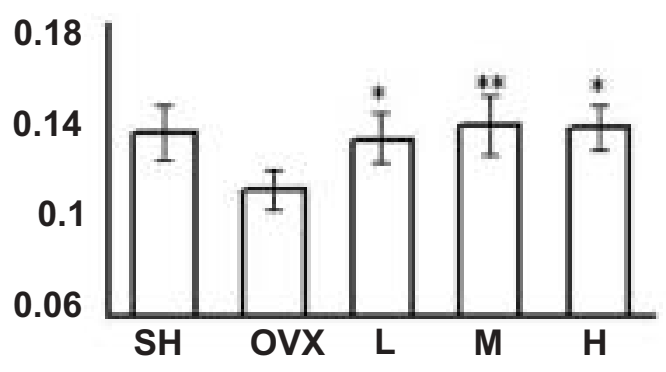

Figure 4: Bone calcium content changes. OVX caused significant bone calcium decrease. After 12 weeks' treatment with genistein, bone calcium was $96.3,99.3$ and $99.0 \%$ of $\mathrm{SH}$ group. The effect of genistein at middle $(9 \mathrm{mg} / \mathrm{kg})$ and high $(18 \mathrm{mg} / \mathrm{kg})$ doses on bone calcium was especially significant ( $P<0.05$ vs low dose group). Data is expressed as the mean \pm SE. ${ }^{*} P<0.05,{ }^{* *} P<0.01$ vs OVX. ${ }^{\#} P<0.05$ vs $\mathrm{M}, \mathrm{H}$ groups. L: low dose (4.5 mg/kg), M: mid-dose (9 mg/kg), H: high dose (18 $\mathrm{mg} / \mathrm{kg})$.

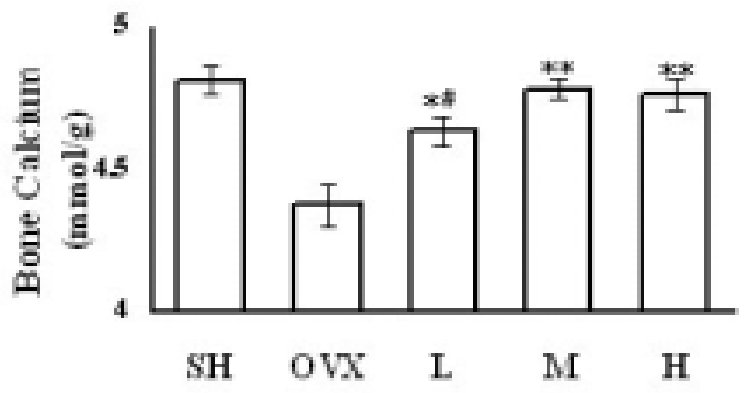


Figure 5: Bone phosphorus content changes. OVX also reduced bone phosphorous, the effect being reversed by genistein treatment. After drug administration for 12 weeks, bone phosphorus was $98.8,96.9$ and $95.1 \%$ of SH group. Data is expressed as the mean SE. ${ }^{*} P<0.05$ vs $\mathrm{SH},{ }^{* *} P<0.01 \mathrm{vs} \mathrm{SH}$. L: low dose $(4.5 \mathrm{mg} / \mathrm{kg})$, M: mid-dose $(9 \mathrm{mg} / \mathrm{kg})$, $\mathrm{H}$ : high dose $(18 \mathrm{mg} / \mathrm{kg})$.

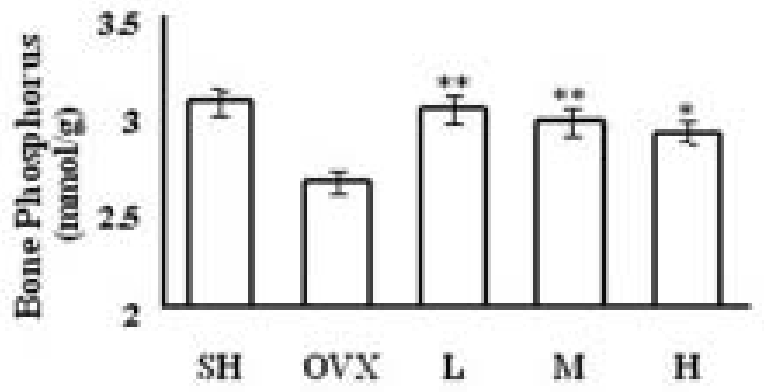

formation and calcification and have been shown to differentiate into mature cells following treatment with $17 \beta$-estradiol. ${ }^{\text {[20] }}$ Our results showed that $10^{-6} \mathrm{M}$ genistein effectively promoted osteoblastic cell proliferation and differentiation.

OVX rat models are the most commonly used experimental animal models for studies on the mechanisms of osteoporosis and on the efficacy of potential therapeutic agents for the treatment and prevention of osteoporosis. ${ }^{[21]}$ We found that orally administrated genistein increased femoral and tibial BMD and bone calcium and phosphorus levels which were all decreased by OVX,. Genistein displayed a good bone-protective effect especially at the mid- and high doses (9 and $18 \mathrm{mg} / \mathrm{kg})$.

In conclusion, this study demonstrates the beneficial effects of genistein on osteoblastic cells and other bone-specific biochemical parameters in an animal model of estrogen-deficiency. Our evidence clearly demonstrates that genistein could be considered as a natural alternative to hormone replacement therapy for the prevention and treatment of bone loss in postmenopausal women. Further studies will be needed to determine whether genistein derivatives have direct actions on bone as well as to identify the mechanism of genistein's action.

\section{References}

1. Arjmandi BH, Alekel L, Hollis BW, Amin D, Stacewicz-Sapuntzakis M, Guo P, et al. Dietary soybean protein prevents bone loss in an ovariectomized rat model of osteoporosis. J Nutr 1996;126:161-7.
2. Barnes S. Phyto-oestrogens and osteoporosis: What is a safe dose? $\mathrm{Br} \mathrm{J}$ Nutr 2003;89:S101-8.

3. Olsson $\mathrm{HL}$, Ingvar $\mathrm{C}$, Bladstrom $\mathrm{A}$. Hormone replacement therapy containing progestins and given continuously increases breast carcinoma risk in Sweden. Cancer 2003;97:1387-92.

4. Albertazzi P, Purdie $D$. The nature and utility of the phytoestrogens: A review of the evidence. Maturitas 2002:42:173-85.

5. Russell L, Hicks GS, Low AK, Shepherd JM, Brown CA. Phytoestrogens: A viable option?. Am J Med Sci 2002;324:185-8.

6. Coxam V. Prevention of osteopaenia by phyto-oestrogens: Animal studies. $\mathrm{Br} \mathrm{J}$ Nutr 2003;89:S75-85.

7. Hidaka S, Okamoto Y, Miyazaki K, Uesugi T. Evaluation of a soybean product fujiflavone P40 as an antiosteoporotic agent in rats. Phytother Res 2003;17:1129.

8. Lee YB, Lee HJ, Kim KS, Lee JY, Nam SY, Cheon SH, et al. Evaluation of the preventive effect of isoflavone extract on bone loss in ovariectomized rats. Biosci Biotechnol Biochem 2004;68:1040-5.

9. Mathey J, Puel C, Kati-Coulibaly S, Bennetau-Pelissero C, Davicco MJ, Lebecque $\mathrm{P}$, et al. Fructooligosaccharides maximize bone-sparing effects of soy isoflavoneenriched diet in the ovariectomized rat. Calcif Tissue Int 2004;75:169-79.

10. Ososki AL, Kennelly EJ. Phytoestrogens: A review of the present state of research. Phytother Res 2003;17:845-69.

11. Lonard DM, Smith CL. Molecular perspectives on selective estrogen receptor modulators (SERMs): Progress in understanding their tissue-specific agonist and antagonist actions. Steroids 2002;67:15-24.

12. Crisafulli $A$, Altavilla $D$, Squadrito $G$, Romeo A, Adamo EB, Marini R, et al. Effects of the phytoestrogen genistein on the circulating soluble receptor activator of nuclear factor kappaB ligand-osteoprotegerin system in early postmenopausal women. J Clin Endocrinol Metab 2004;89:188-92.

13. Cotter A, Cashman KD. Genistein appears to prevent early postmenopausal bone loss as effectively as hormone replacement therapy. Nutr Rev 2003;61:346-51.

14. Muthyala RS, Ju YH, Sheng S, Williams LD, Doerge DR, Katzenellenbogen BS, et al. Equol, a natural estrogenic metabolite from soy isoflavones: Convenient preparation and resolution of R- and S-equols and their differing binding and biological activity through estrogen receptors alpha and beta. Bioorg Med Chem 2004;12:1559-67.

15. Chen X, Garner SC, Quarles LD, Anderson JJ. Effects of genistein on expression of bone markers during MC3T3-E1 osteoblastic cell differentiation. J Nutr Biochem 2003:14:342-9.

16. Khalil DA, Lucas EA, Smith BJ, Soung DY, Devareddy L, Juma S, et al. Soy isoflavones may protect against orchidectomy-induced bone loss in aged male rats. Calcif Tissue Int 2005;76:56-62.

17. Mosmann T. Rapid colorimetric assay for cellular growth and survival: Application to proliferation and cytotoxicity assays. J Immunol Met 1983;65:55-63.

18. Bradford MM. A rapid and sensitive method for the quantitation of microgram quantities of protein utilizing the principle of protein-dye binding. Anal Biochem 1976;72:248-54.

19. Yamaguchi M, Oishi $H$, Suketa $Y$. Stimulatory effect of zinc on bone formation in tissue culture. Biochem Pharmacol 1987;36:4007-12.

20. Armour KE, Ralston SH. Estrogen upregulates endothelial constitutive nitric oxide synthase expression in human osteoblast-like cells. Endocrinology 1998;139:799802.

21. Frost HM, Jee WS. On the rat model of human osteopenias and osteoporoses. Bone Miner 1992:18:227-36. 